\title{
A Remotely Powered Implantable Biomedical System With Location Detector
}

\author{
Enver G. Kilinc, Student Member, IEEE, Mehrdad A. Ghanad, Student Member, IEEE, \\ Franco Maloberti, Fellow, IEEE, and Catherine Dehollain, Member, IEEE
}

\begin{abstract}
An universal remote powering and communication system is presented for the implantable medical devices. The system be interfaced with different sensors or actuators. A mobile external unit controls the operation of the implantable chip and reads the sensor's data. A locator system is proposed to align the mobile unit with the implant unit for the efficient magnetic power transfer. The location of the implant is detected with $6 \mathrm{~mm}$ resolution from the rectified voltage level at the implanted side. The rectified voltage level is fedback to the mobile unit to adjust the magnetic field strength and maximize the efficiency of the remote powering system. The sensor's data are transmitted by using a free running oscillator modulated with on-off key scheme. To tolerate large data carrier drifts, a custom designed receiver is implemented for the mobile unit. The circuits have been fabricated in $0.18 \mathrm{um} \mathrm{CMOS} \mathrm{technology.} \mathrm{The} \mathrm{remote} \mathrm{powering}$ link is optimized to deliver power at $13.56 \mathrm{MHz}$. On chip voltage regulator creates $1.8 \mathrm{~V}$ from a $0.9 \mathrm{~V}$ reference voltage to supply the sensor/actuator blocks. The implantable chip dissipates $595 \mu \mathrm{W}$ and requires $1.48 \mathrm{~V}$ for start up.
\end{abstract}

Index Terms-CMOS analog circuit design, data communication, implantable biomedical system, implantable medical device, inductive link, integrated circuits, location detection, locator, power management, remote powering, wireless power transfer.

\section{INTRODUCTION}

$\mathbf{F}$ UTURE trend in patient monitoring is to use implanted devices capable of measuring relevant vital parameters and transmit them to an external data processing station [1]-[4]. This offers multiple advantages, the small and light weight implants are more comfortable for the patient. Moreover, the possibility of a low power local data processing with data storage allows to achieve continuous long-term monitoring with a stand-alone implanted device. In addition, a mobile external station is removed for the comfort of the patient after the implanted device is charged and the data is received. Animal research is another application of implantable electronics [5], [6]. As an example, the effect of the new drugs on animals can be verified [7].

Manuscript received September 12, 2013; revised January 14, 2014 and April 01, 2014; accepted April 24, 2014. Date of publication June 27, 2014; date of current version January 23, 2015. This project was supported by Swiss National Funding (SNF) through Sinergia and PlaCiTUS Initiatives. This paper was recommended by Associate Editor P. Mercier.

E. G. Kilinc, M. A. Ghanad, and C. Dehollain are with the Institute of Electrical Engineering, Ecole Polytechnique Fédérale de Lausanne, Lausanne, Vaud 1015, Switzerland (e-mail: enver.kilinc@epfl.ch; catherine.dehollain@epfl.ch).

F. Maloberti is with the Institute of Electrical Engineering, Universitá degli Studi di Pavia, 27100 Pavia, Italy (e-mail: franco.maloberti@unipv.it).

Color versions of one or more of the figures in this paper are available online at http://ieeexplore.ieee.org.

Digital Object Identifier 10.1109/TBCAS.2014.2321524

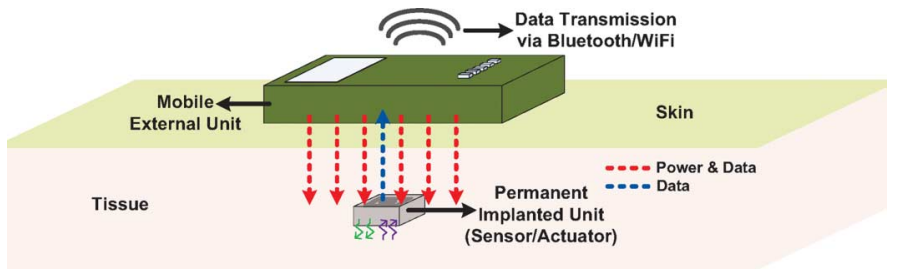

Fig. 1. Conceptual design of stand-alone implantable system.

The key requirements for an implanted system are the size, the autonomy and the data communication capability. The system size normally should be less than $1 \mathrm{~cm}^{3}$ [8]-[10]. Autonomy is important for operations which requires long monitoring periods. Usually, using batteries is undesirable because of weight, size and life time issues. Therefore, power harvesting or remote powering solutions are necessary. However, harvesting the power inside the living body is insufficient to power multi-sensor systems with short range two-way communication. Remote powering provides a reliable solution to continuously monitor the patient.

Fig. 1 illustrates a stand-alone implanted system. A permanent implanted unit is placed under the skin inside the body and consists of sensors or actuators. To avoid using the batteries, the implanted system is activated and charged by a mobile external unit. The operation of the implanted system is initiated by relocating the implant with the mobile external unit. The measured data is transmitted from the implanted unit to the external unit. For the comfort of the patient, the external unit is removed after finishing the operation. The external unit also configures the implant by down-link communication. The mobile external unit communicates with a control unit such as a smartphone or a base-station via bluetooth and WiFi.

This paper presents an universal platform for implantable multi-sensor systems. Basic blocks for a micro-integrated system, with possibility of being assembled as a System In Package, SIP, are experimentally verified. In addition a locator system is proposed to find the location of the fixed platform in the body to power and communicate efficiently. The paper is organized as follows: Section II explains the details of the optimized remote powering link. The external and the internal electronics of the remote powering is discussed in Section III. Section IV overviews of the proposed locator system. Section V describes the electronics of data communication. The simulation and measurement results are presented in Section VI. Finally, Section VII concludes the paper. 


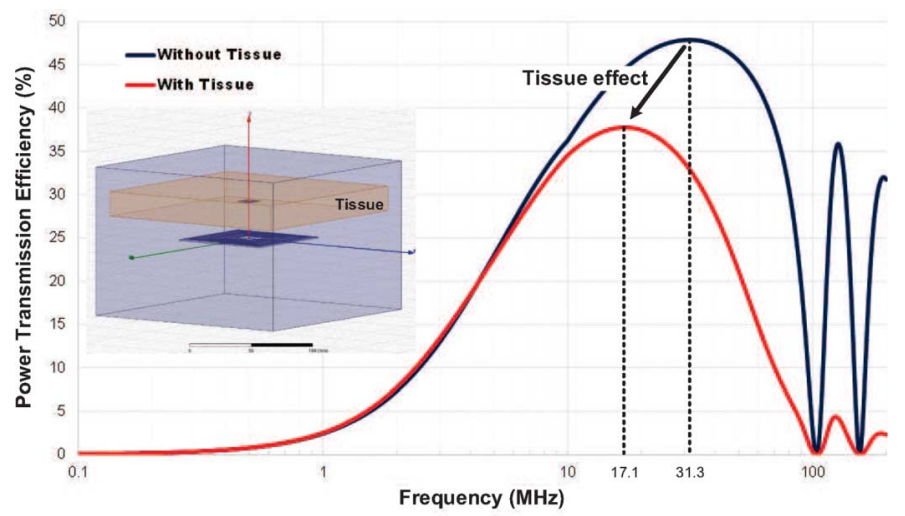

Fig. 2. Tissue effect on optimal power transmission frequency.

\section{Optimized Remote POWERING LINK FOR IMPLANTABLE SYSTEM}

The power consumption of typical implanted system with advanced sensing and processing blocks is estimated to be 2-3 mW. Accordingly, we have used magnetic coupling for remote powering, because for short distance (less than $10 \mathrm{~cm}$ ) it is the most effective and the penetration in the body is better compared to the other methods [11], [12]. On the other hand, the size constraints limit the area of implanted coil to 12 by $12 \mathrm{~mm}^{2}$. In order to design optimal coils, number of turns and conductor width and spacing are critical elements [13], [14]. In addition, it is necessary to find the optimal frequency and transmitting coil size. The frequency choice aims to maximize the induced voltage which is given by

$$
V_{\text {ind }}=\mu_{0} \cdot \mu_{r} \cdot A \cdot N \cdot \omega \cdot H_{\mathrm{eff}}
$$

where $\mu_{0}, \mu_{r}, A, N, \omega$, and $H_{\text {eff }}$ are the magnetic permeability constant of vacuum, the relative permeability of implanted medium, the loop area of the implant coil, its number of turns, the angular frequency of the effective magnetic coupling, and the effective magnetic field strength, respectively. The induced voltage is proportional to the frequency. However, AC resistance of a coil also increases as the conductive losses due to skin and proximity effects start to dominate after a certain frequency [15]. The frequency choice is also crucial to deliver the power efficiently in the body. The dielectric properties of the body tissues change with the frequency. Accordingly, the penetration depth of a signal inside the body decreases with frequency [16].

The optimal power transmission frequency depends on the kind of the body tissues, the distance between the transmitter and receiver and a possible air gap. In order to determine a value suitable for a generic use, assuming a tissue (fat) with thickness of $2 \mathrm{~cm}$, a 3-D simulation [17] determines an optimal frequency. Fig. 2 shows the tissue effect on the optimal power transmission frequency and also the power transmission efficiency. The optimal frequency shifts from $31.3 \mathrm{MHz}$ to $17.1 \mathrm{MHz}$ considering the tissue effect. Accordingly, the power transmission frequency is moved to the closest ISM band of $13.56 \mathrm{MHz}$ which is authorized for the inductive remote powering applications [18].

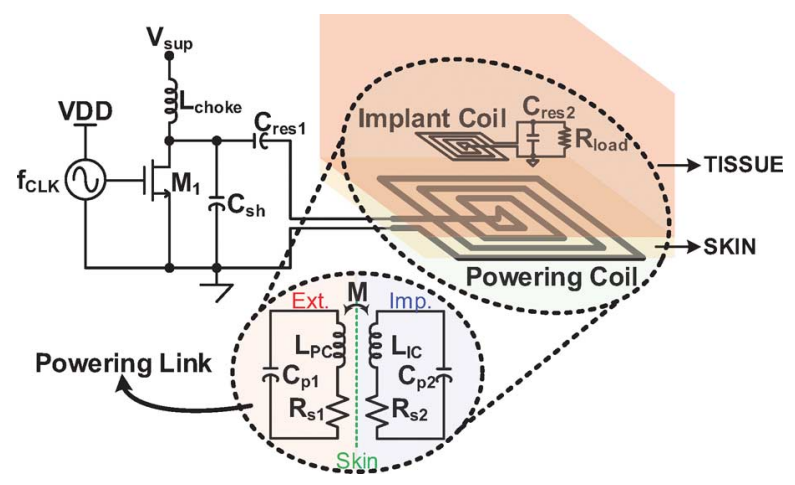

Fig. 3. Magnetically coupled remote powering link and external link driver.

The power transmission efficiency of the remote powering link is maximized when the coils are tuned at the same operation frequency. Assuming that the coils are tuned to the same frequency $\left(\omega_{e x t}=\omega_{i m p}\right)$, the maximum power transmission efficiency for a certain load can be expressed by [19]

$$
\eta_{\max }=\frac{1}{1+\frac{1}{k_{12}^{2} Q_{P C} Q_{I C}}}
$$

where $k_{12}, Q_{P C}$ and $Q_{I C}$ are the coupling coefficient, the quality factors of the unloaded powering coil and the unloaded implant coil, respectively. The maximum power efficiency can be obtained by maximizing not only the coupling factor, but also the quality factors of the coils [20], [21].

A geometric optimization of the remote powering link is required to obtain an efficient remote powering link. However, dependency of remote powering efficiency to many geometric parameters of the coils, e.g., number of turns, width of the conductors and spacing between them, outer and inner diameters and also the coupling between the coils, makes the optimization extremely complicated.

The geometric parameters of the coils are swept to obtain the optimal coil pair. The lumped model parameters of the optimized coils which are shown in Fig. 3 are extracted by using analytical equations and a field solver software [22], [23]. The power transfer efficiency of the remote powering link is calculated by using the equation in [19]. The geometric parameters of the coils are characterized in a 3-D electromagnetic field simulation software [17]. Finally, the coils are produced on printed circuit board (PCB) for reliability and reproducibility and characterized for operation frequency.

Based on the aforementioned optimization method, we designed the optimal remote powering link. Table I represents the design parameters of the optimized coil geometries and the measurement results of the optimized coils.

Fig. 3 also shows the external link driver. Its output power depends on the amplitude of the supply voltage $\left(V_{\text {sup }}\right)$ which is adjusted to deliver the required power level to implant. A power feedback control described with more details in Section III, controls $V_{\text {sup }}$ to continuously supply sufficient power to the implant despite coupling variations. 
TABLE I

DESIGN AND Optimal CoILs PARAMETERS

\begin{tabular}{|c|c|cc|}
\hline Parameter & Unit & Powering & Implant \\
\hline Operation frequency $\left(f_{0}\right)$ & $\mathrm{MHz}$ & \multicolumn{3}{|c|}{13.56} \\
Distance between coils $\left(d_{12}\right)$ & $\mathrm{mm}$ & \multicolumn{2}{|c|}{30} \\
Outer dimension & $\mathrm{mm}$ & 80 & 12 \\
Number of turns & - & 9 & 8 \\
Conductor width & $\mathrm{mm}$ & 2 & 0.2 \\
Conductor spacing & $\mathrm{mm}$ & 1.6 & 0.2 \\
Conductor height & $\mu \mathrm{m}$ & 30 & 20 \\
Inductance $\left(L_{P C}, L_{I C}\right)$ & $\mu \mathrm{H}$ & 4.32 & 0.78 \\
Series resistance $\left(R_{s 1}, R_{s 2}\right)$ & $\Omega$ & 3.81 & 0.89 \\
Parasitic capacitance $\left(C_{p 1}, C_{p 2}\right)$ & $\mathrm{pF}$ & 2.44 & 3.46 \\
Reson. capacitance $\left(C_{r e s 1}, C_{r e s 2}\right)$ & $\mathrm{pF}$ & 29.4 & 181 \\
Coupling factor $\left(k_{12}\right)$ & - & \multicolumn{3}{|c}{0.02} \\
\end{tabular}

\section{Electronics of Remote Powering}

The remotely powered systems consist of two parts. The external part generates the magnetic field for the implanted system and receives the data transmitted by the implanted system. The internal part creates a supply voltage for the implanted system from the induced current and communicates with the external part.

The external unit is composed of a link driver, a receiver, a supply controller, and a powering coil. The external link driver is chosen as a class-E type of amplifier to drive the powering coil due to the high achievable drain efficiency. Fig. 3 shows the class-E power amplifier together with the remote powering link. The link is presented by $L_{P C}, L_{I C}$, and $M$ the powering and implant coils and mutual inductance, respectively. The $C_{\text {res1 }}$ and $C_{\text {res2 }}$ capacitors are used for tuning the coils for operation frequency. In addition, $R_{\text {load }}$ represents the load of the remote powering link which is the input resistance of the implanted rectifier. The $M_{1}, L_{\text {choke }}$, and $C_{\text {sh }}$ present the switching transistor of the amplifier, the choke inductor and the shunt capacitor, respectively. $L_{\text {choke }}$, and $C_{\text {sh }}$ values are chosen in order to maximize the power efficiency of the power amplifier [24]. The operation frequency of the amplifier is fixed to $13.56 \mathrm{MHz}$ by an external oscillator circuit.

The output power $\left(P_{\text {out }}\right)$ delivered to the load seen by the power amplifier $\left(R_{L}\right)$ is proportional to [25]

$$
P_{\text {out }} \propto \frac{V_{\text {sup }}^{2}}{R_{L}} .
$$

Due to the weak coupling between the powering and the implant coils, the reflected impedance of the implanted side to the external side is low [20]. Therefore, $R_{L}$ is dominated by the series resistance of the powering coil at the operation frequency $\left(R_{L} \approx R_{s 1}\right)$.

A low supply voltage $\left(V_{\text {sup }}\right)$ is necessary for the power amplifier to deliver few $\mathrm{mWs}$ to the implanted system due to low $R_{L}$ value. $V_{\text {sup }}$ is controlled by the supply controller according to the power feedback data in order to change the transferred power level. Fig. 4 illustrates the power feedback control loop. The supply controller is composed of a DC-DC converter which assures high power efficiency [26], [27]. A NMOS switch $\left(M_{\mathrm{DC}-\mathrm{DC}}\right)$ which is controlled by the power feedback data, defines $V_{\text {sup }}$ voltage according to the duration of the pulse. When the power level in the implanted system is

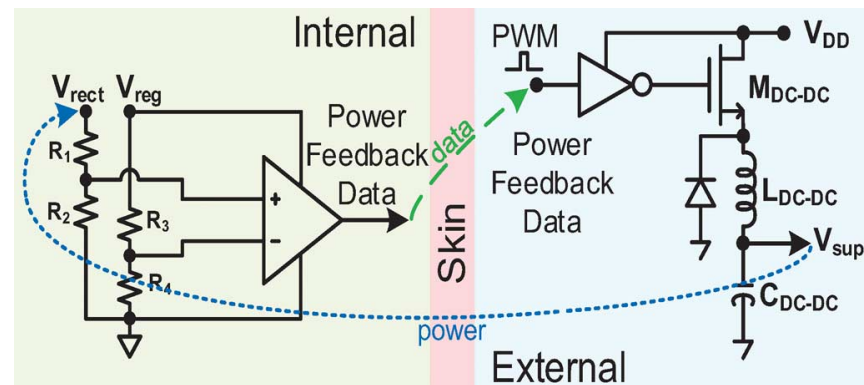

Fig. 4. Power feedback control loop.

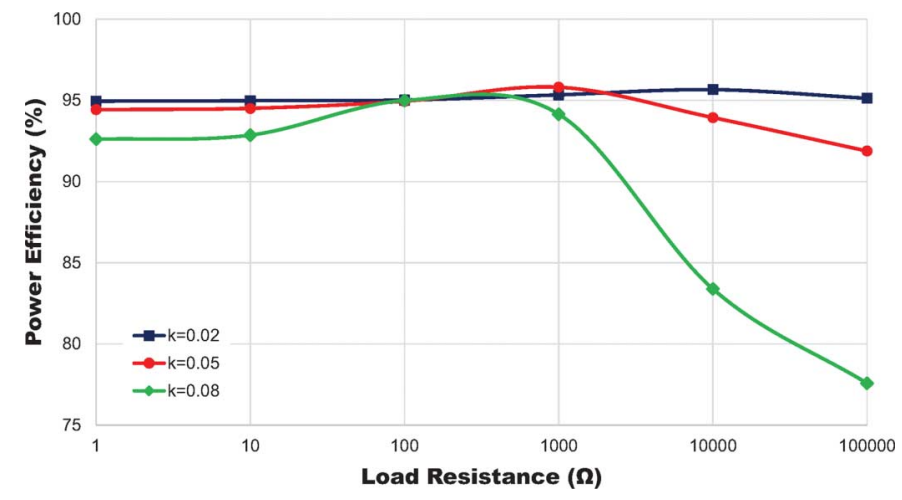

Fig. 5. Simulated power efficiency of amplifier vs. load resistance of implanted system for different coupling coefficients.

insufficient, the power feedback data will be "0". The data is inverted and $M_{\mathrm{DC}-\mathrm{DC}}$ starts to charge the capacitor. Consequently, $V_{\text {sup }}$ voltage increases until the power feedback data becomes " 1 ". When the data is " 1 ", $M_{\mathrm{DC}-\mathrm{DC}}$ is turned off and $V_{\text {sup }}$ voltage starts to decrease.

The variation of the load resistance or the coupling coefficient does not significantly change performance of the power feedback loop and the efficiency of the power amplifier. Fig. 5 shows the simulated power efficiency of the amplifier versus the load resistance of the implanted system.

The delay from detecting the rectifier output voltage level to updating the supply voltage of the power amplifier creates additional voltage ripples on the output voltage of the rectifier that could result in stability issues. The amplitude of the ripples mainly depends on the power feedback update rate and the DC-DC converter frequency response [26]. The update rate is limited by the communication data rate. In addition, the values of the inductor $L_{\mathrm{DC}-\mathrm{DC}}$ and the capacitor $C_{\mathrm{DC}-\mathrm{DC}}$ have been chosen experimentally to minimize the ripples on the rectifier output [27].

The internal unit consists of an implant coil, a passive fullwave rectifier, a voltage regulator, and a voltage level detection circuit [7]. In addition, a reference generation, a power on reset, a multiplexer, and a low-power transmitter are integrated on the same platform.

The active rectifiers are highly efficient for high-power loads. However, they are not suitable for low-power applications which demand less than $3 \mathrm{~mW}$ [28], [29]. The passive rectifiers are more effective for the low-power applications [30], [31]. On the other hand, the passive rectifiers suffer from the high voltage drop across a diode-connected transistor 
which reduces the power conversion efficiency [32]. In order to decrease the voltage drop, the high-threshold transistor can be replaced by a low or zero threshold transistor. However, the backward leakage current is increased due to the non-disabled transistor. Accordingly, the power efficiency of the rectifier decreases. In this study, the induced signal in the implant coil is rectified and $V_{\text {rect }}$ voltage is charged on the storage capacitor by a passive full-wave rectifier. The rectifier uses the charge-storage technique which decreases the forward voltage drop on the diode connected high-threshold transistor as presented in [7]. This technique reduces the gate-source voltage $\left(V_{\mathrm{GS}}\right)$ of the transistor and allows to achieve high power conversion efficiency at low-power loads.

A low-dropout (LDO) voltage regulator suppresses the ripples and generates a clean and stable supply voltage $\left(V_{\text {reg }}\right)$ for the implanted system. In order to obtain high Power Supply Rejection Ratio (PSRR) on $V_{\text {reg }}$ voltage, the reference voltage of the voltage regulator $\left(V_{\text {ref_LDO }}\right)$ should also have an acceptable PSRR value. Moreover, $V_{\text {ref_LDO }}$ voltage should be constant and stable for wide range of supply variation where $V_{\text {rect }}$ could change by more than $1 \mathrm{~V}$. The reference generation circuit is a CMOS self-biased reference circuit [33]. Fig. 6 shows the proposed reference generation circuit together with start-up. When $V_{\text {rect }}$ voltage increases, the current on the both $M_{3}$ and $M_{4}$ transistors are increased. Therefore, the $V_{\mathrm{GS} 10}$ voltage also increases. This voltage increase is compensated by the decrease on $V_{\mathrm{GS} 7}$ voltage. Accordingly, $V_{\text {ref_LDO }}$ voltage stays constant for wide range of $V_{\text {rect }}$ voltage. In addition, a self-biased cascode current mirror is proposed to enhance the PSRR. The output resistance of the cascode current mirror is defined as

$$
r_{o}=g_{m_{M 6}} r_{o_{M 6}} r_{o_{M 4}}
$$

where $r_{o}, r_{o_{M 6}}, r_{o_{M 4}}$ is the output resistance of the cascode stage, the output resistance of $M_{6}$ transistor, and the output resistance of $M_{4}$ transistor, respectively. In addition, $g_{m_{M 6}}$ represents the transconductance of the $M_{6}$ transistor. The output resistance of the cascode current mirror is increased by the gain of the $M_{6}$ transistor compared to the single stage current mirror which introduces more fluctuation on the current of each branch and also $V_{\text {ref_LDO }}$ voltage. Fig. 6 shows the comparison of PSRR between the single and cascode current mirror. PSRR is enhanced by more than $25 \mathrm{~dB}$ at low frequencies and $5.5 \mathrm{~dB}$ at $27.12 \mathrm{MHz}$ frequency. In addition, the cascode transistors are biased by the self-biased technique which decreases the voltage drop across the current mirror and allows to operate at low supply voltage with cascaded transistors.

The level detection circuit compares the output voltage of the rectifier $\left(V_{\text {rect }}\right)$ with a reference voltage as illustrated in Fig. 4. When $V_{\text {rect }}$ is under the reference voltage, the supply sensor sends the power feedback data as logic " 0 ". This increases the delivered power level to the implanted unit and results in a higher rectifier voltage. On the other hand, the power feedback data will be "1", when the rectifier voltage is higher than the reference voltage. The voltage level detection circuit is implemented by a comparator and the voltage levels are adjusted by the voltage dividers. The sensor system collects the data from

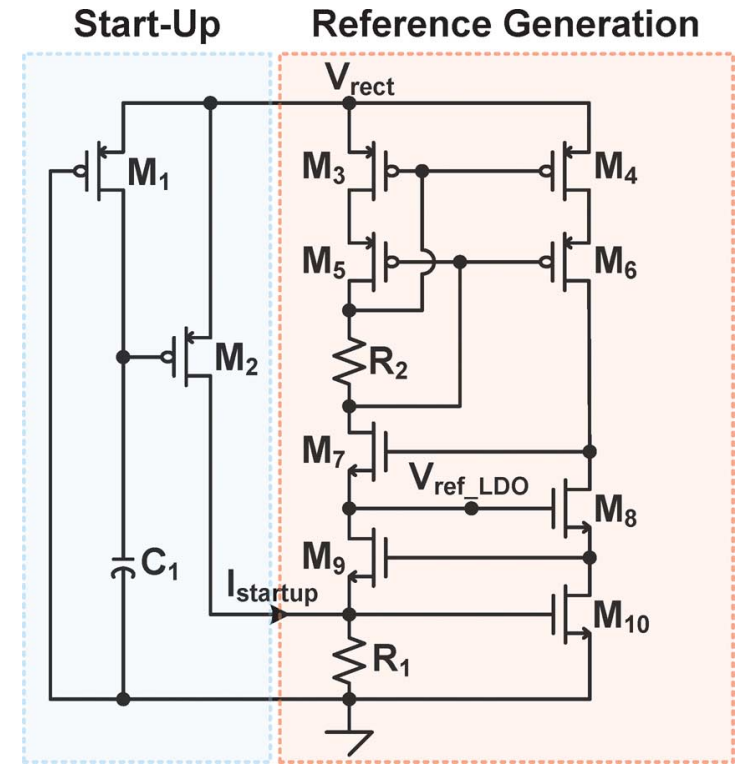

Fig. 6. Proposed reference generation circuit with start-up.

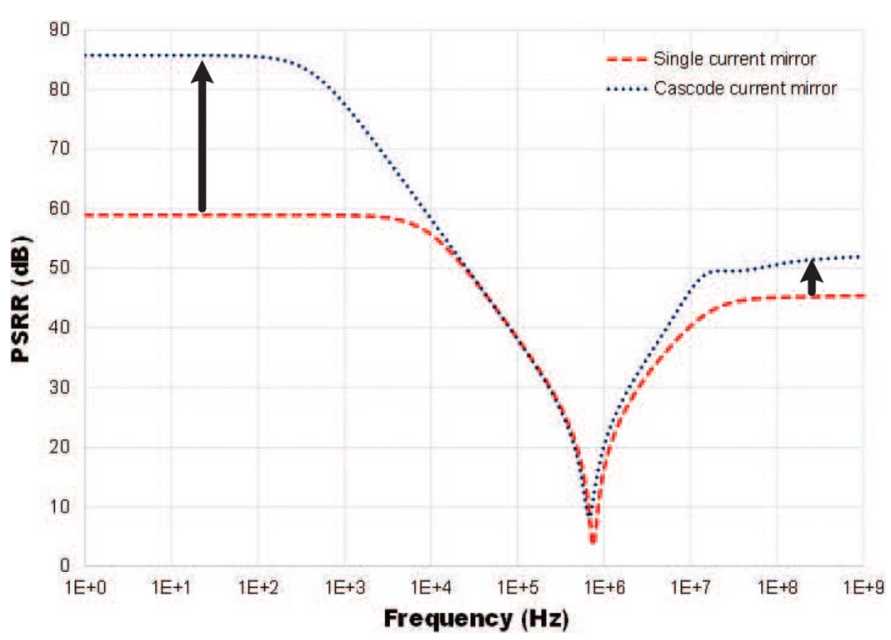

Fig. 7. Comparison of PSRR between single and cascode current mirror.

different types of electrochemical, $\mathrm{pH}$, and temperature sensors. The data source is switched between the sensors and the supply sensor by a multiplexer and the data is delivered to the transmitter.

In order to prevent malfunctioning and failures in the circuits especially in digital circuits due to the insufficient supply voltage, a Power on Reset (PoR) circuit is implemented. The level of $V_{\text {reg }}$ is tracked by the PoR circuit [34]. The PoR circuit sends "power-up" signal and enables all circuits when the supply voltage is high enough. In addition, the PoR disables the all chip and sends "power-down" signal when $V_{\text {reg }}$ voltage level decreases under a certain level where the circuits perform improperly. Moreover, the PoR circuit cancels all the operation if the supply voltage drops under a certain level or the power transmission is interrupted suddenly. All the operations are restarted by the PoR circuit when the supply voltage reaches a required level.

Fig. 8 shows the circuit schematic of Power on Reset. When $V_{\text {reg }}$ supply voltage increases, the current and eventually $V_{\mathrm{GS}_{1}}$ 


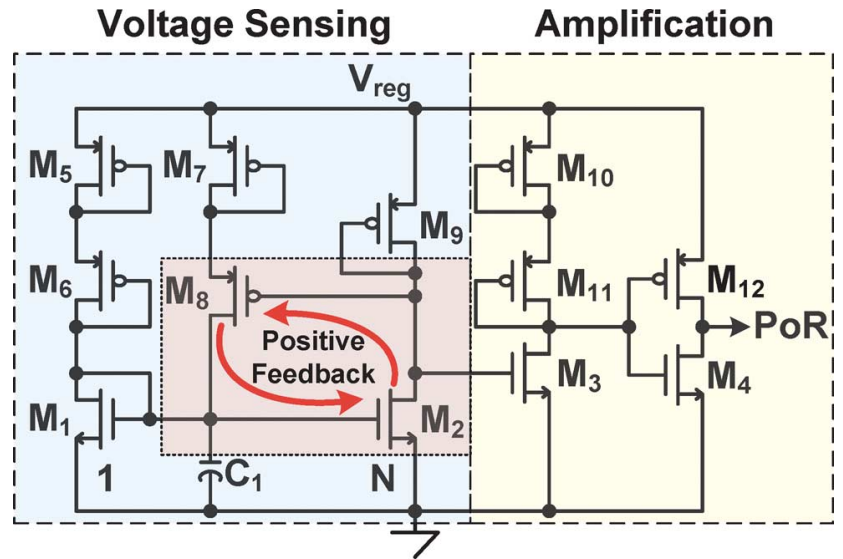

Fig. 8. Circuit schematic of Power on Reset.

voltage of $M_{1}$ transistor increases. The increase on $V_{\mathrm{GS}_{1}}$ voltage is delayed by charging the $C_{1}$ capacitance. When $V_{\mathrm{GS}_{2}}$ voltage reaches to threshold voltage of $M_{2}$ transistor, $M_{2}$ transistor turns on and $\mathrm{N}$ times current of $M_{1}$ transistor starts to flow over $M_{2}$ transistor. Accordingly, the drain voltage $V_{D S_{2}}$ of $M_{2}$ transistor decreases and is tracked by $M_{8}$ transistor. Transistor $M_{8}$ produces a positive feedback which increases $V_{\mathrm{GS}_{2}}$ voltage which also increases the drain current of $M_{2}$. Accordingly, the gate voltage $V_{\mathrm{GS}_{3}}$ of $M_{3}$ decreases under threshold voltage of $M_{3}$ and finally $M_{3}$ turns off at a certain $V_{\text {reg }}$ voltage level. Therefore, the input of the inverter converges to $V_{\text {reg }}$ voltage and "power-up" signal is supplied to enable all circuits. The inverter is used to obtain rail-to-rail signal. On the other hand, "power-down" signal is created to disable the circuits by the same mechanism which is performed reversely while $V_{\text {reg }}$ voltage decreases.

\section{Proposed Locator System}

During the magnetic power transmission, the coupling between the coils changes according to the positions of the coils with respect to each other. Therefore, there is a strong correlation between the misalignment and the coupling of the coils. The transmitted power needs to be increased to obtain a constant received power when the implant coil moves from the center to the edges of the powering coil. Accordingly, the supply voltage of the powering coil driver is increased to compensate the misalignment. Fig. 9 shows the effect of misalignment on the coupling coefficient and the required supply voltage of the driver which are normalized with respect to the concentric coil alignment values.

The permanent implanted device needs to be recharged and communicate with the mobile external device as shown in Fig. 1. However, the implanted device could move inside the body and it would be necessary to relocate it. The supply voltage of coil driver is tracked for constant received power by the power feedback loop. Also, this supply voltage is used to relocate the implanted device. Fig. 10 shows the proposed locator which can be used to find the location of the implantable device in the body. The locator tracks the supply voltage of the external coil driver and the LED ladder indicates the amount of the misalignment between the coils. The supply voltage of the driver

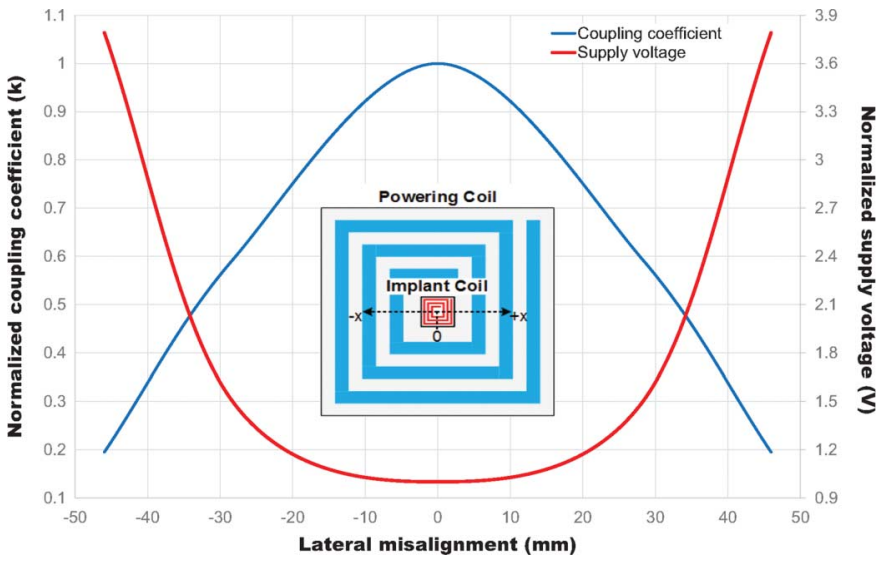

Fig. 9. Misalignment effect on coupling coefficient and supply voltage.
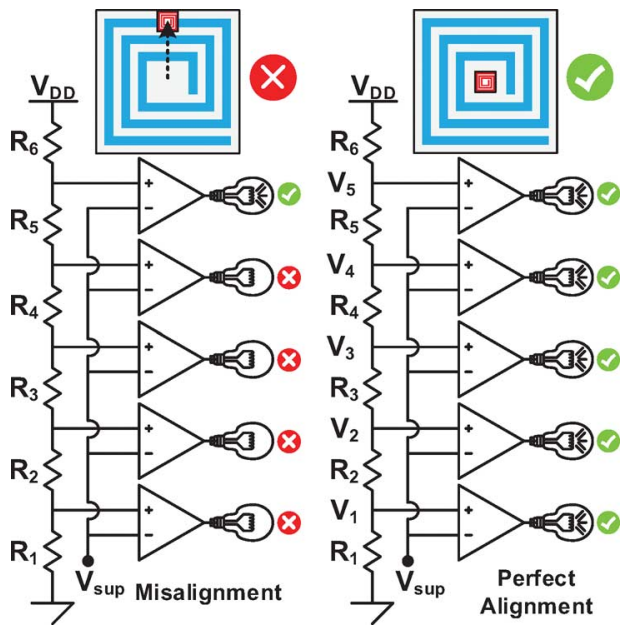

Fig. 10. Aligning mobile unit with implantable device using a locator circuit.

decreases non-linearly when the mobile unit moves towards to the center of implanted device as shown in Fig. 9. Therefore, a resistor ladder with non-linear voltage levels is implemented so each LED turns on for a fixed amount of misalignment. Using comparators, the supply voltage of the power amplifier is compared with the resistive ladder voltage levels. When the mobile unit moves towards to the implanted device, the supply voltage of the coil driver decreases and the LEDs on the indicator turn on respectively. Finally, all the LEDs turn on when the perfect alignment is achieved as shown in Fig. 10.

\section{Electronics of Data Communication}

The quality factors of the powering and the implant coils are crucial to improve the power transfer efficiency. However, the high quality factor limits the high data rate communication by reducing the bandwidth. Therefore, the data communication deteriorates the power transmission efficiency when the remote powering and the communication share the same channel. In order to obtain efficient power transmission and high data rate communication simultaneously, a different frequency channel $(868 \mathrm{MHz})$ which is defined by the regulations is used for data communication [35].

The power consumption of the implanted system is generally dominated by active transmitter power dissipation. Generating 


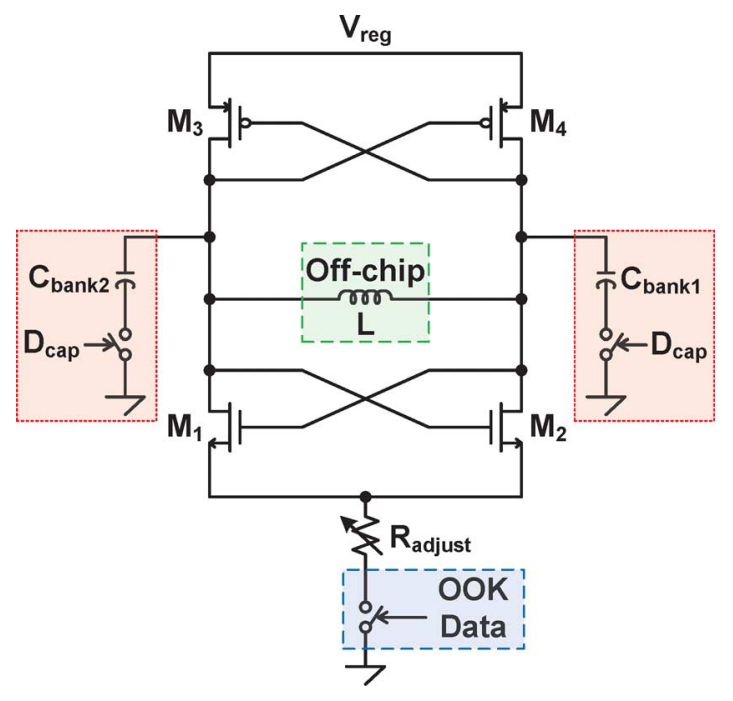

Fig. 11. Circuit schematic of free-running oscillator as data transmitter.

data carrier with frequency synthesizers results in high power dissipation due to power hungry dividers. Frequency multiplication [36] and employing MEMS resonators [37] are proposed as low-power methods to generate stable carriers. In this work, the data is transmitted without generating a stable carrier [38], [39]. Fig. 11 shows the circuit schematic of the free-running oscillator as a data transmitter. The OOK modulated signal is obtained by switching the bias current. Both NMOS and PMOS cross-coupled pairs are used to reuse the bias current and enhance the negative resistance for a given bias current. The transistors are biased in weak inversion region where the transconductance of the transistor is maximized for a specific drain current. The circuit consumes $180 \mu \mathrm{A}$ at $1.8 \mathrm{~V}$ supply voltage. The bias current can be modified to adjust the carrier level and communication range.

The free-running oscillator directly drives the antenna and RF power amplifier is omitted to further reduce power dissipation. The inductor $(L)$ in the LC tank of the oscillator is implemented off-chip to also serve as a transmitting antenna. The radiation efficiency of an antenna is proportional to its effective area which is limited by the implant size. Fig. 12 shows the loop antenna of the free-running oscillator transmitter. The antenna which has a diameter of $11 \mathrm{~mm}$ is optimized in an electromagnetic simulation program (Momentum) [40]. The simulated inductance value and the quality factor of the loop antenna are $28 \mathrm{nH}$ and 204, respectively. Two capacitive banks which are controlled by a digital block are also added to LC tank for tuning the oscillation frequency to the operation frequency band $(868 \mathrm{MHz})$. The total estimated radiation efficiency of this antenna is $3 \%$ in free space [41]. Therefore, the estimated radiated power from the implant in free space is $-31 \mathrm{dBm}$ according to the simulated AC power dissipation of $30 \mu \mathrm{W}$ in the LC tank.

Commercially available ISM band receivers tolerate only small frequency drifts. However, the low-power transmitter of the implanted system has a large frequency deviation which needs to be compensated by the receiver. Therefore, the receiver is designed to demodulate signals with large carrier drifts. Fig. 13 shows the block diagram of the proposed custom

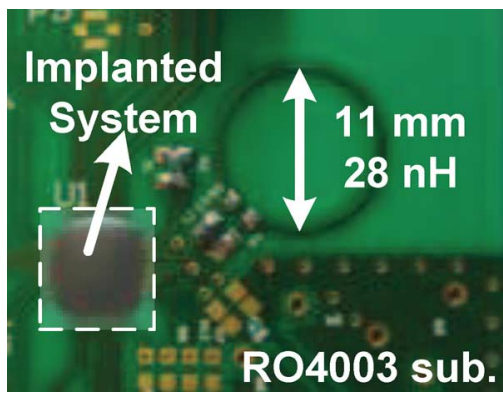

Fig. 12. Loop antenna of free-running oscillator transmitter on a test board.

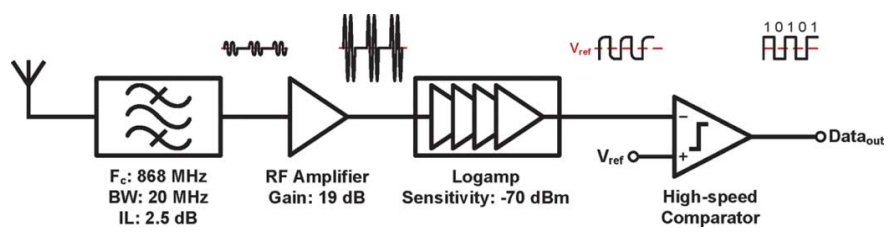

Fig. 13. Block diagram of proposed custom designed receiver.

designed receiver. The received signal is filtered by a ceramic bandpass filter which serves a high quality factor and sharp transition band. The filter has a $20 \mathrm{MHz}$ bandwidth which is wide enough to detect the carrier signal with frequency drifts due to temperature and LC tank variation of the implanted transmitter.

The data is transmitted as On-Off-Keying (OOK) modulated signal. Therefore, a logarithmic amplifier (logamp) follows the RF amplifier in order to detect these RF bursts. The logamp works as an envelope detector and converts the input power level to an output voltage. Finally, the output of the logamp is compared to a reference voltage $\left(V_{\text {ref }}\right)$ with the help of a high-speed comparator with a hysteresis for further immunity to noise. The data rate of the receiver can be as high as 1.5 Mbps. The total power dissipation of the receiver is $152 \mathrm{~mW}$. The minimum detectable signal at the input of the receiver is $-86 \mathrm{dBm}$ limited by the sensitivity of the logamp. The required signal to noise ratio (SNR) and the sensitivity can be adjusted by changing the comparators reference voltage $\left(V_{\text {ref }}\right)$.

In order to obtain reliable measurement results from sensors, each sensor needs to be calibrated and biased properly due to the different environmental conditions. Therefore, some low-data rate commands are transmitted from the external unit to the implanted unit by modulating amplitude of the powering signal. The commands are received by a ASK demodulator in the implanted unit and the demodulated information is processed by the digital block.

\section{Simulation AND MEASUREMENT Results}

In order to validate the performance of the remotely powered implantable sensor system, an experimental setup is created. Fig. 14 shows the experimental setup of the remote powering system for the implantable sensor unit. The circuits are fabricated in $0.18 \mu \mathrm{m}$ standard CMOS process. The rectifier and the regulator circuits are designed with $3.3 \mathrm{~V}$ thick transistors to increase the reliability and the longevity of the circuits. Fig. 15 represents the micrograph of the fabricated circuits. 


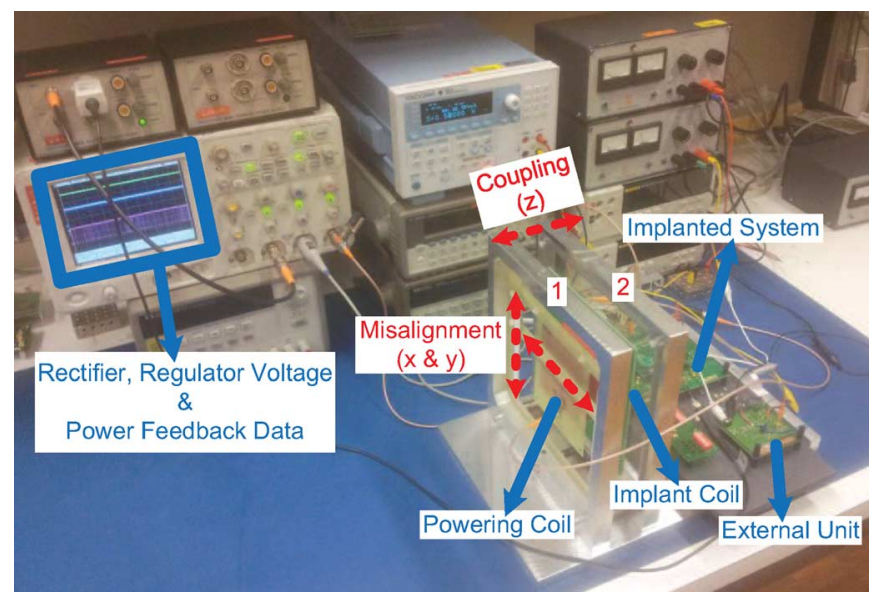

Fig. 14. Experimental setup of remote powering system and data communication.

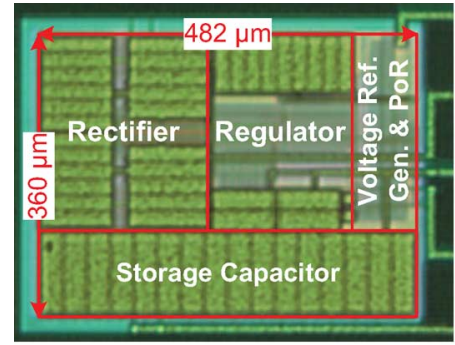

a)

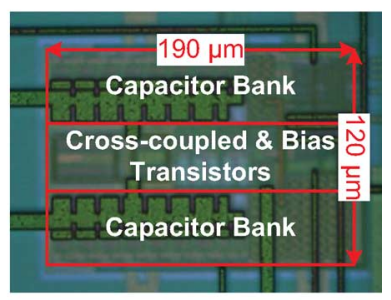

b)
Fig. 15. Micrograph of the fabricated (a) power management blocks and (b) free-running oscillator.

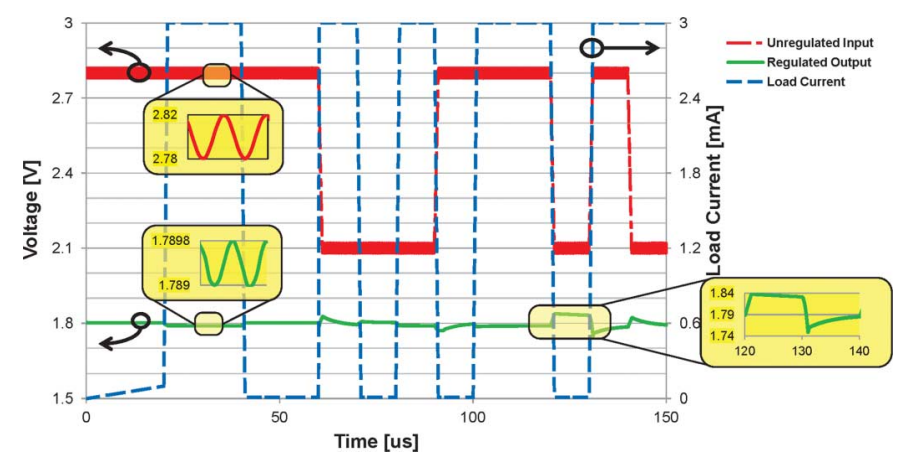

Fig. 16. Post-layout simulation result of LDO voltage regulator.

The measured power efficiency of the integrated passive fullwave rectifier is $80 \%$ at $2 \mathrm{~mW}$ load while generating $2.2 \mathrm{~V}$ at the output of the rectifier. The reference generation circuit creates $0.9 \mathrm{~V}$ reference voltage $\left(V_{\text {ref_LDO }_{\text {LD }}}\right)$ and has power supply rejection (PSRR) response of $78.6 \mathrm{~dB}$ at DC and $47.8 \mathrm{~dB}$ at 27.12 MHz. Fig. 16 shows the post-layout transient simulation result of the LDO voltage regulator. The regulated output voltage has maximum ripple of $50 \mathrm{mV}(1.79-1.84 \mathrm{~V})$ when the unregulated input of the regulator decreases from $2.8 \mathrm{~V}$ to $2.1 \mathrm{~V}$ and the load current decreases from $3 \mathrm{~mA}$ to $100 \mu \mathrm{A}$. The ripple rejection of the high-speed LDO voltage regulator is more than $60 \mathrm{~dB}$ at $27.12 \mathrm{MHz}$. The PoR enables the circuits when $V_{\text {reg }}$ voltage reaches to $1.48 \mathrm{~V}$. The PoR disables the circuits if $V_{\text {reg }}$

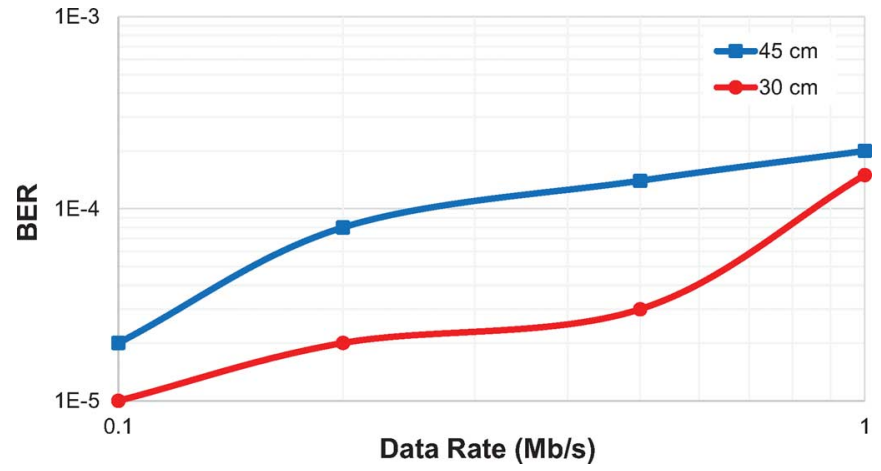

Fig. 17. BER performance of communication link for different communication distances.

TABLE II

POWER CONSUMPTION OF IMPLANTABLE ELECTRONICS

\begin{tabular}{|c|c|c|}
\hline Circuit & Power $(\mu \mathbf{W})$ & Dist. (\%) \\
\hline Voltage regulator & 234 & 13.8 \\
Reference generation & 10.9 & 0.6 \\
Power feedback comparator & 11.2 & 0.7 \\
Power on reset & 14.4 & 0.9 \\
Transmitter & 324 & 19.1 \\
Total & 595 & 35.0 \\
Rectifier load power & 1700 & 100 \\
\hline
\end{tabular}

voltage decrease under 1.45 V. Fig. 17 shows Bit Error Rate (BER) performance of the OOK transmitter and the custom designed receiver for different communication distances. In order to measure the BER, more than 90 million random bits are created by a FPGA and transmitted across the communication link in air. Table II summarizes the power consumption breakdown of the implantable electronics.

The values of $L_{\text {choke }}$ inductor and the $C_{\mathrm{sh}}$ capacitor as shown in Fig. 3 are optimized in order to maximize the drain efficiency of the amplifier. The remote powering link is optimized for $1.6 \mathrm{k} \Omega$ load resistance which also emulates the input resistance of the rectifier. The maximum remote powering efficiency is achieved as $21.7 \%$ at $1.6 \mathrm{k} \Omega$ load by using $180 \mathrm{nH}$ inductance and $320 \mathrm{pF}$ capacitance values when the distance between the coils $\left(d_{12}\right)$ is $3 \mathrm{~cm}$.

The 2-D lateral misalignment effect on power transfer efficiency is verified by moving the powering coil according to the implant coil as shown in Fig. 14. The platform allows to simulate different coupling conditions during the measurement. The platform have two docks ( 1 and 2) where the powering and the implanted coils are placed respectively. In addition, the powering coil can move on the dock 1 to simulate the 2-D lateral misalignment.

Fig. 18 shows the overall power efficiency distribution on the powering coil which includes the power efficiencies of the power amplifier, the remote powering link, and the integrated rectifier in order to obtain $2.2 \mathrm{~V}$ output voltage from the rectifier for $1.7 \mathrm{~mW}$ load power. The overall efficiency changes drastically from $16.8 \%$ to less than $1 \%$ when the implanted unit moves from center to edges. This nonuniform power transmission gives rise to change in the received power at the implanted unit. As a 


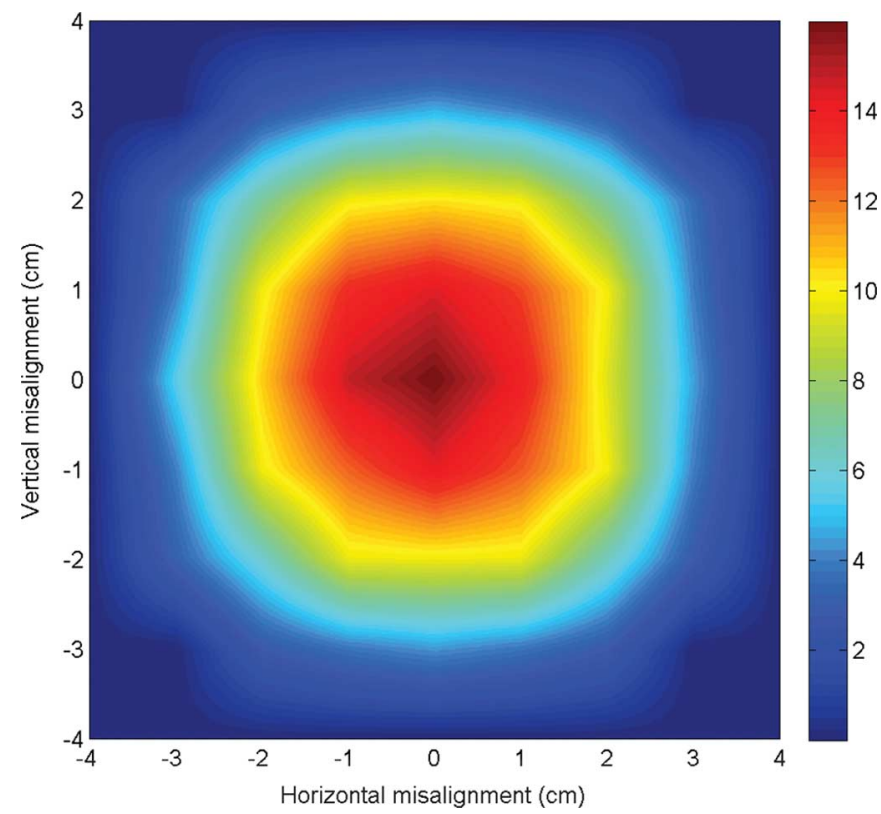

Fig. 18. Overall power efficiency distribution on powering coil $\left(d_{12}=3 \mathrm{~cm}\right)$.

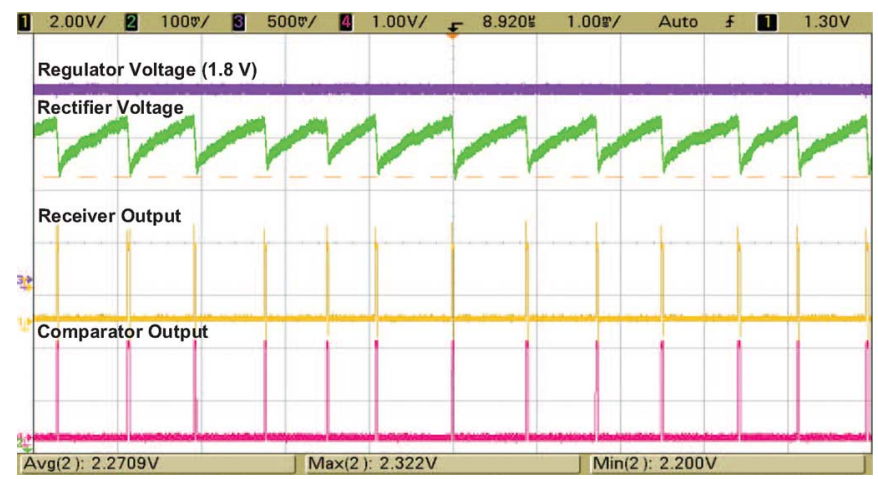

Fig. 19. Dynamic power adaptation technique.

result, the implanted unit cannot continue its operation if the received power drops under a threshold level. On the other hand, the circuits can be damaged if the received power increases too much. Therefore, the transmitted power level must be adapted dynamically by the power feedback control loop as shown in Fig. 4. Fig. 19 shows the dynamic power adaptation technique. When the coupling between the coils changes, the power feedback loop adjusts the transmitted power level. Accordingly, the rectifier voltage is kept between $2.20 \mathrm{~V}$ and $2.32 \mathrm{~V}$ by the feedback loop.

The magnetic field strength decreases from the center to the edges of the powering as shown in Fig. 18. As a result the power amplifier supply voltage follows the inverse of magnetic field trend to keep the implanted rectifier output at $2.27 \mathrm{~V}$. Fig. 20 illustrates the power amplifier supply voltage change due to the horizontal and vertical lateral misalignments. The PA supply voltage needs to be increased from $0.28 \mathrm{~V}$ to $0.45 \mathrm{~V}$ to obtain constant voltage at the output of the rectifier while the implanted unit moves from center to edge of the powering coil by $3 \mathrm{~cm}$.

Fig. 21 shows the locator system to relocate the implanted device. The supply voltage of the power amplifier changes non-linearly. In addition, the power transmission efficiency on the pow-

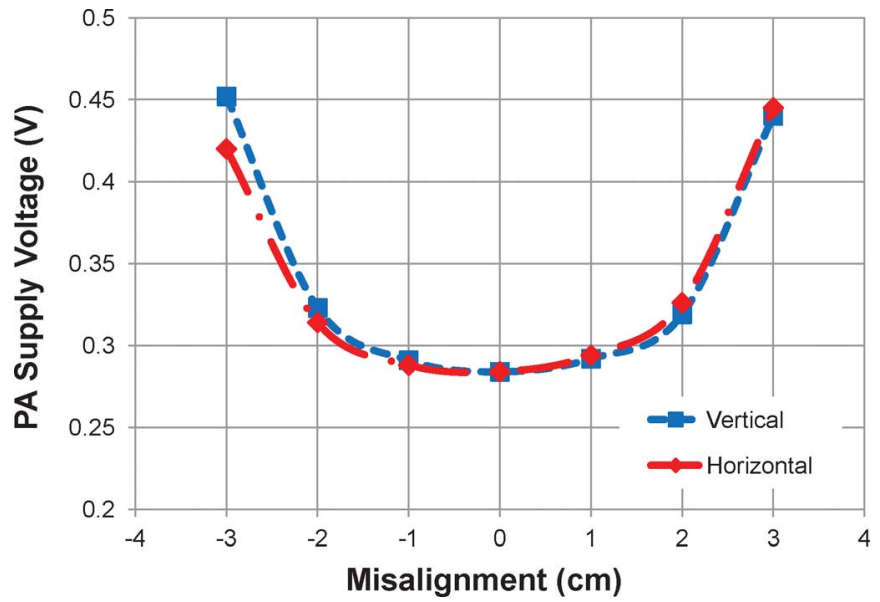

Fig. 20. Power amplifier supply voltage vs. lateral misalignment.

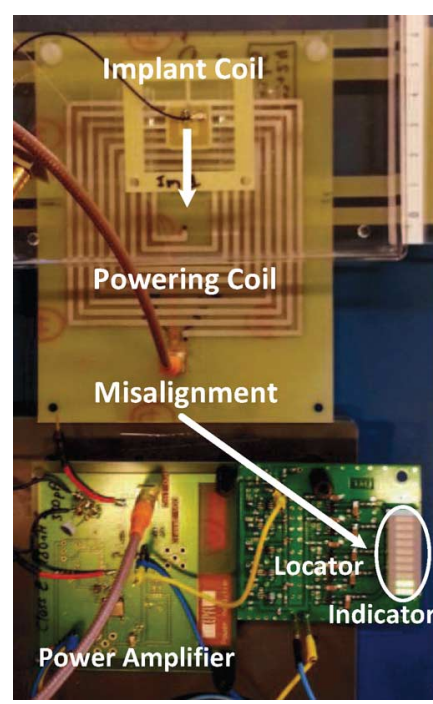

(a)

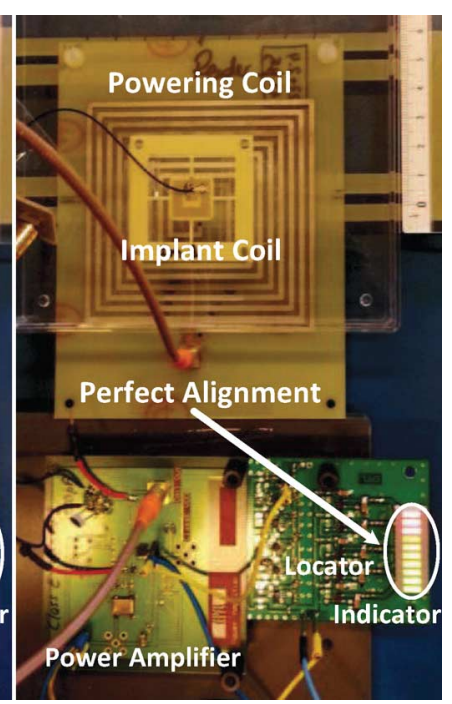

(b)
Fig. 21. Locator system. (a) Misalignment case. (b) Perfect alignment case.

ering coil decreases extremely on the edges less than $1 \%$ and the power amplifier needs to transmit high power which damages the circuit. Accordingly, the locator system is designed to keep the misalignment below $3 \mathrm{~cm}$. The locator system has five non-linear voltage levels and each voltage level is chosen experimentally to represent approximately $0.6 \mathrm{~cm}$ on the powering coil. When the implanted device and mobile unit is not aligned properly, the indicator shows the distance required for perfect alignment. All the LEDs are turned on when the perfect alignment is achieved and the power transmission efficiency is maximized as shown in Fig. 21.

As a case study, this implantable remote powering and data communication micro-system can be used for bio-sensors. Biosensors are helpful to monitor endogenous molecules (e.g., glucose, ATP) and drugs in the body. These bio-sensors require a circuit which needs $711 \mu \mathrm{W}$ of power to calibrate and readout [42]. Our micro-system can supply up to $1.7 \mathrm{~mW}$ of power with $16.8 \%$ of power efficiency and has $0.6 \mathrm{~mW}$ power consumption. Therefore, $1.1 \mathrm{~mW}$ of power budget is quite sufficient for operation of the bio-sensor readout and calibration circuit. 
TABLE III

Summary OF ReMOtely POWEREd IMPLANTABLE Micro-SySTEM

\begin{tabular}{|c|c|c|}
\hline Parameter & Unit & Value \\
\hline Technology & - & UMC 0.18 $\mu \mathrm{m}$ \\
Implantable & - & Yes \\
Total power consumption & $\mu \mathrm{W}$ & 595 \\
Powering type & - & Remote powering \\
Powering frequency & $\mathrm{MHz}$ & 13.56 \\
Powering distance & $\mathrm{mm}$ & 30 \\
Powering efficiency & $\%$ & $16.8^{\star} @ 1.7 \mathrm{~mW} \mathrm{load}$ \\
Rectifier power efficiency & $\%$ & $80 @ 2 \mathrm{~mW} \mathrm{load}$ \\
Voltage regulator PSRR & $\mathrm{dB}$ & $60 @ 27.12 \mathrm{MHz}$ \\
Supply voltage & $\mathrm{V}$ & 1.8 \\
Reference voltage PSRR & $\mathrm{dB}$ & $47.8 @ 27.12 \mathrm{MHz}$ \\
PoR enable/disable voltage & $\mathrm{V}$ & $1.48 / 1.45$ \\
Uplink communication & - & OOK \\
Uplink com. frequency & $\mathrm{MHz}$ & 869 \\
Uplink com. data rate & $\mathrm{Mb} / \mathrm{s}$ & up to 1.5 \\
Uplink com. distance & $\mathrm{cm}$ & 45 \\
Downlink communication & - & ASK \\
Downlink com. frequency & $\mathrm{MHz}$ & 13.56 \\
Locator system resolution & $\mathrm{mm}$ & 6 \\
\hline
\end{tabular}

* Including the power efficiencies of the power amplifier, powering link and rectifier

TABLE IV

PERFormance COMPARISON OF REMOTE POWERING LinK

\begin{tabular}{|c|c|c|c|c|}
\hline Reference & $\begin{array}{c}\text { Diameter } \\
\text { (Ex./In.)(mm) }\end{array}$ & $\begin{array}{c}\text { Dist. } \\
\text { (mm) }\end{array}$ & $\begin{array}{c}\text { Freq. } \\
\text { (MHz) }\end{array}$ & Eff. \\
\hline$[43]$ & $60 / 20$ & 30 & 0.7 & $36 \%$ \\
{$[44]$} & $30 / 30$ & 10 & 6.785 & $51 \%$ \\
{$[45]$} & $69 / 20$ & 10 & 1 & $41.2 \%$ \\
{$[46]$} & $64 / 22$ & 20 & 0.7 & $82 \%$ \\
{$[47]$} & $43 / 10$ & 10 & 8 & $54.8 \%$ \\
This Work & $80 / 12$ & 30 & 13.56 & $21.7 \%{ }^{\star}$ \\
\hline
\end{tabular}

* Including power efficiencies of power amplifier, powering link

TABLE V

PERFormance COMPARISON OF SHORT RANGe COMMUNICATION

\begin{tabular}{|c|c|c|c|c|c|}
\hline Reference & $\begin{array}{c}\text { Data Rate } \\
(\mathbf{M b} / \mathbf{s})\end{array}$ & $\begin{array}{c}\text { Dist. } \\
\mathbf{( c m )}\end{array}$ & $\begin{array}{c}\text { Freq. } \\
\mathbf{( M H z )}\end{array}$ & $\begin{array}{c}\text { Power } \\
(\mathbf{m W})^{\star}\end{array}$ & BER \\
\hline$[39]$ & 0.33 & 13 & 433 & 1.81 & 0.003 \\
{$[48]$} & 1 & - & 916.5 & 3.8 & 0.001 \\
{$[49]$} & 136 & 20 & 2460 & 3 & 0.0017 \\
This Work & 0.5 & 30 & 868 & 0.32 & $3 \cdot 10^{-5}$ \\
\hline
\end{tabular}

* Transmitter power consumption only

Table III summarizes the performance of the remotely powered implantable micro-system. Furthermore, Tables IV and V compare this work with the recently reported remotely powered systems and the short range communication systems in the literature, respectively.

\section{CONCLUSION}

The paper presents an universal remote powering and communication systems for the implantable medical devices to be used along with different sensor/actuator interfaces. A permanent implanted device is placed under the skin and stores the measured data. A mobile external unit charges the implanted device and receives the data from the implant. A locator system is proposed to relocate the implant in the body with $6 \mathrm{~mm}$ resolution for the efficient power transfer. A significant feature is the detection of the location of the implant. Moreover, this custom designed receiver tolerates large data carrier drifts of the transmitter. The fabricated implantable electronics works with a relatively low supply voltage and provides all the functions needed for the external link thanks to an optimized remote power supply capable to operate over $3 \mathrm{~cm}$ distance. The power required by the implantable electronics including the one for the wireless communication is just $0.6 \mathrm{~mW}$.

\section{ACKNOWLEDGMENT}

The authors would like to thank to F. Mazzilli, G. Yilmaz, and $\mathrm{O}$. Atasoy for their valuable feedback and help.

\section{REFERENCES}

[1] E. Wilkins et al., "Integrated implantable device for long-term glucose monitoring," Biosens. Bioelectron., vol. 10, pp. 485-494, 1995.

[2] S. Carrara et al., "Multi-panel drugs detection in human serum for personalized therapy," Biosens. Bioelectron., vol. 26, no. 9, pp. 3914-3919, 2011.

[3] M. Sawan, Y. Hu, and J. Coulombe, "Wireless smart implants dedicated to multichannel monitoring and microstimulation," IEEE Circuits Syst. Mag., vol. 5, no. 1, pp. 21-39, 2005.

[4] C. Boero et al., "New technologies for nanobiosensing and their applications to real-time monitoring," in Proc. IEEE Biomedical Circuits and Systems Conf., 2011, pp. 357-360.

[5] N. Chaimanonart and D. J. Young, "A wireless batteryless in vivo EKG and body temperature sensing microsystem with adaptive RF powering for genetically engineered mice monitoring," in Proc. Int. Solid-State Sensors, Actuators and Microsystems Conf., 2009, pp. 1473-1476.

[6] A. Prasad and M. Sahin, "Characterization of neural activity recorded from the descending tracts of the rat spinal cord," Frontiers Neurosci., vol. 4, no. 21, pp. 1-7, June 2010.

[7] E. G. Kilinc et al., "Remotely powered telemetry system with dynamic power-adaptation for freely moving animals," in Proc. IEEE Biomedical Circuits and Systems Conf., 2012, pp. 260-263.

[8] M. Azin et al., "A miniaturized system for spike-triggered intracortical microstimulation in an ambulatory rat," IEEE Trans. Biomed. Eng., vol. 58, no. 9, pp. 2589-2597, 2011.

[9] C. T. Wentz et al., "A wirelessly powered and controlled device for optical neural control of freely-behaving animals," J. Neural Eng., vol. 8 , no. 4,2011

[10] E. G. Kilinc et al., "Short-range remote powering for long-term implantable sensor systems in freely moving small animals," in Proc. IEEE Sensors Conf., 2013, pp. 1787-1790.

[11] E. G. Kilinc et al., "Short range remote powering of implanted electronics for freely moving animals," in Proc. IEEE 11th Int. New Circuits and Systems Conf., 2013, pp. 1-4, 2013.

[12] D. C. Yates, A. S. Holmes, and A. J. Burdett, "Optimal transmission frequency for ultralow-power short-range radio links," IEEE Trans. Circuits Syst. I, Reg. Papers, vol. 51, no. 7, pp. 1405-1413, 2004.

[13] C. M. Zierhofer and E. S. Hochmair, "Geometric approach for coupling enhancement of magnetically coupled coils," IEEE Trans. Biomed. Eng., vol. 43, no. 7, pp. 708-714, 1996.

[14] U. M. Jow and M. Ghovanloo, "Modeling and optimization of printed spiral coils in air, saline, and muscle tissue environments," IEEE Trans. Biomed. Circuits Syst., vol. 3, pp. 339-347, 2009.

[15] J. Ferreira, "Improved analytical modeling of conductive losses in magnetic components," IEEE Trans. Power Electron., vol. 9, no. 1, pp. 127-131, 1994.

[16] S. Gabriel, R. W. Lau, and C. Gabriel, "The dielectric properties of biological tissues: II. Measurements on the frequency range $10 \mathrm{~Hz}$ to 20 GHz," Phys. Med. Biol., vol. 41, pp. 2251-2269, 1996.

[17] Ansys, Inc., USA., HFSS-3D Full-Wave Electromagnetic Field Simulation. [Online]. Available: http://www.ansoft.com/products/hf/hfss

[18] Inductive Applications ERC/REC 70-03, in Annex 9, Oct. 2009.

[19] K. M. Silay, C. Dehollain, and M. Declercq, "Improvement of power efficiency of inductive links for implantable devices," in Proc. Ph.D. Research in Microelectronics and Electronics Conf., 2008, pp. 229-232.

[20] E. G. Kilinc et al., "FoM to compare the effect of ASK based communications on remotely powered systems," in Proc. Ph.D. Research in Microelectronics and Electronics Conf., 2011, pp. 29-32.

[21] K. V. Schuylenbergh and R. Puers, Inductive Powering. New York, NY, USA: Springer, 2009. 
[22] E. G. Kilinc, C. Dehollain, and F. Maloberti, "Design and optimization of inductive power transmission for implantable sensor system," in Proc. Int. Workshop Symbolic and Numerical Methods, Modeling and Applications to Circuit Design, 2010, pp. 1-5.

[23] Fast Field Solvers [Online]. Available: http://www.fastfieldsolvers.com

[24] N. O. Sokal, "Class-E RF power amplifiers," QEX Mag., no. 204, pp. 9-20, Jan./Feb. 2001.

[25] T. H. Lee, The Design of CMOS Radio-Frequency Integrated Circuits. Cambridge, U.K.: Cambridge Univ. Press, 2004.

[26] M. Kiani and M. Ghovanloo, "An RFID-based closed loop wireless power transmission system for biomedical applications," IEEE Trans. Circuits Syst. II, Exp. Briefs, vol. 57, no. 4, pp. 260-264, 2010.

[27] G. Wang et al., "Design and analysis of an adaptive transcutaneous power telemetry for biomedical implants," IEEE Trans. Circuits Syst. I, Reg. Papers, vol. 52, no. 10, pp. 2109-2117, 2005.

[28] H. Lee and M. Ghovanloo, "An integrated power-efficient active rectifier with offset-controlled high speed comparators for inductively-powered applications," IEEE Trans. Circuits Syst. I, Reg. Papers, vol. 58, no. 8, pp. 1749-1760, 2011.

[29] O. Atasoy and C. Dehollain, "Remote powering realization for smart orthopedic implants," in Proc. 10th IEEE Int. Conf. New Circuits and Systems, 2012, pp. 521-524.

[30] J.-P. Curty et al., "A model for $\mu$-Power rectifier analysis and design," IEEE Trans. Circuits Syst. I, Reg. Papers, vol. 52, no. 12, pp. $2771-2779,2005$.

[31] H. Nakamoto et al., "Passive UHF RF identification CMOS tag IC using ferroelectric RAM in $0.35 \mu \mathrm{m}$ technology," IEEE J. Solid-State Circuits, vol. 42, no. 1, pp. 101-110, 2007

[32] F. Mazzilli et al., "Design methodology and comparison of rectifiers for UHF-band RFIDs," in Proc. IEEE Radio Frequency Integrated Circuits Symp., 2010, pp. 505-508.

[33] A. M. Sodagar et al., "Fully integrated CMOS power regulator for telemetry-powered implantable biomedical microsystems," in Proc. IEEE Custom Integrated Circuits Conf., 2006, pp. 659-662.

[34] M. Mi, RFID Radio Circuit Design in CMOS [Online]. Available: http://uqu.edu.sa/files2/tiny_mce/plugins/filemanager/files/4220086

[35] Non-spesific Short Range Devices ERC/REC 70-03, in Annex 1, Oct. 2012.

[36] J. Pandey and B. P. Otis, "A sub-100 W MICS/ISM band transmitter based on injection-locking and frequency multiplication," IEEE $J$. Solid-State Circuits, vol. 46, no. 5, pp. 1049-1058, 2011.

[37] Y. H. Chee et al., "An ultra-low-power injection locked transmitter for wireless sensor networks," IEEE J. Solid-State Circuits, vol. 41, no. 8 , pp. 1740-1748, 2006.

[38] J. L. Bohorquez et al., "A $350 \mathrm{uW}$ CMOS MSK transmitter and 400 uW OOK super-regenerative receiver for medical implant communications," IEEE J. Solid-State Circuits, vol. 44, no. 4, pp. 1248-1259, 2009.

[39] R. Harrison et al., "A low-power integrated circuit for a wireless 100electrode neural recording system," IEEE J. Solid-State Circuits, vol. 42, no. 1, pp. 123-133, 2007.

[40] Agilent Technologies, Inc., USA, Momentum 3D Planar EM Simulator [Online]. Available: http://www.home.agilent.com/en/pc-1887116

[41] J. Pandey et al., "A fully integrated RF-powered contact lens with a single element display," IEEE Trans. Biomed. Circuits Syst., vol. 4, no. 6, pp. 454-461, Dec. 2010.

[42] S. S. Ghoreishizadeh, S. Carrara, and G. De Micheli, "A configurable IC to contol, readout, and calibrate an array of biosensors," in Proc. Eur. Conf. Circuit Theory and Design, 2013, pp. 1-4.

[43] M. Catrysse, B. Hermans, and R. Puers, "An inductive power system with integrated bidirectional data transmission," in Proc. 17th Eurosensors, Sep. 21-24, 2003, pp. 843-846.

[44] M. W. Baker and R. Sarpeshkar, "Feedback analysis and design of RF power links for low-power bionic systems," IEEE Trans. Biomed. Circuits Syst., vol. 1, no. 1, pp. 28-38, Mar. 2007.

[45] U.-M. Jow and M. Ghovanloo, "Design and optimization of printed spiral coils for efficient transcutaneous inductive power transmission," IEEE Trans. Biomed. Circuits Syst., vol. 1, no. 3, pp. 193-202, Sep. 2007.

[46] A. K. RamRakhyani, S. Mirabbasi, and M. Chiao, "Design and optimization of resonance-based efficient wireless power delivery systems for biomedical implants," IEEE Trans. Biomed. Circuits Syst., vol. 5, no. 1 , pp. 48-63, Feb. 2011.

[47] K. M. Silay, C. Dehollain, and M. Declercq, "A closed-loop remote powering link for wireless cortical implants," IEEE Sensors J., vol. 13 , no. 9, pp. 3226-3235, Sep. 2013.
[48] D. C. Daly and A. P. Chandrakasan, "An energy-efficient OOK transceiver for wireless sensor networks," IEEE J. Solid-State Circuits, vol. 42, no. 5, pp. 1003-1011, May 2007.

[49] J. Jung, S. Zhu, P. Liu, Y.-J. Chen, and D. Heo, "22-pJ/bit energy-efficient 2.4-GHz implantable OOK transmitter for wireless biotelemetry systems: In Vitro experiments using rat skin-mimic," IEEE Trans. Microw. Theory Tech., vol. 58, no. 12, pp. 4102-4111, Dec. 2010.

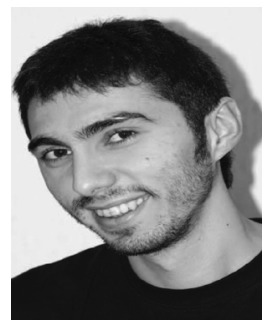

Enver G. Kilinc (S'11) was born in Istanbul, Turkey, in 1985. He received the B.Sc. degree in electronic engineering from Istanbul Technical University (ITU), Istanbul, Turkey, and the M.Sc. degree in electrical and electronic engineering from Ecole Polytechinque Fédérale de Lausanne (EPFL), Lausanne, Switzerland, in 2008 and 2010, respectively.

In March 2010, he joined the Electronics Laboratory at EPFL as a Research Assistant in the field of RFIC design. Currently, he is working toward the $\mathrm{Ph} . \mathrm{D}$. degree on wireless power transmission and radio frequency identification (RFID) with the RFIC Group, Swiss Federale Institute of Technology, Lausanne, Switzerland. His research interests include RF CMOS circuit design for wireless sensor systems and biomedical applications.

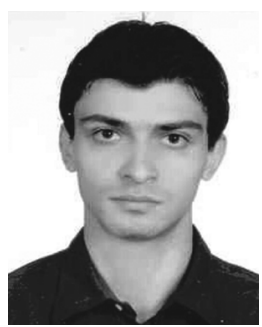

Mehrad A. Ghanad (S'13) received the B.S. degree in electrical engineering from the K. N. Toosi University of Technology, Tehran, Iran, and the M.S. degree in microelectronic engineering from the Sharif University of Technology, Tehran, Iran, in 2007 and 2009 , respectively.

Currently, he is working toward the Ph.D degree with the RFIC Group at Ecole Polytechnique Fédérale de Lausanne (EPFL), Lausanne, Switzerland. His research interests include design of low-power analog and RF CMOS integrated circuits.

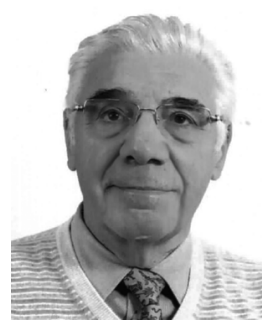

Franco Maloberti (A'84-SM'97-F'96) received the Laurea degree in physics (summa cum laude) from the University of Parma, Parma, Italy, and the Dr. Honoris Causa degree in electronics from Inaoe, Puebla, Mexico, in 1968 and 1996, respectively.

He was a Visiting Professor at ETH-PEL, Zurich, Switzerland, in 1993 and at EPFL-LEG, Lausanne, Switzerland, in 2004. He was Professor of Microelectronics and Head of the Micro Integrated Systems Group, University of Pavia, Pavia, Italy, TI/J. Kilby Analog Engineering Chair Professor at Texas A\&M University, College Station, TX, USA, and the Distinguished Microelectronic Chair Professor at the University of Texas at Dallas. Currently, he is Professor at the University of Pavia and Honorary Professor, University of Macau, Macau, China. His professional expertise is in the design, analysis, and characterization of integrated circuits and analogue digital applications, mainly in the areas of switched capacitor circuits, data converters, interfaces for telecommunication and sensor systems, and portable power management. He has written more than 475 published papers, five books, and holds 32 patents. He has been responsible for many research programs, including 10 ESPRIT projects and served the European Commission in many European Initiatives. He served the Academy of Finland on the assessment of electronic research, and the National Research Council of Portugal for the research activity assessment of Portuguese Universities. He was a member of the Advisory Board of INESC-Lisbon, Portugal. He is the Chairman of the Academic Committee of the Microelectronics Key Laboratory, Macau, China

Prof. Maloberti was VP Region 8 of IEEE CAS (1995-1997), Associate Editor of the IEEE TRANSACTIONS ON CIRCUITS AND SYSTEMS-II: EXPRESS BRRIEFS, President of the IEEE Sensor Council (2002-2003), IEEE CAS BoG member (2003-2005), and VP Publications IEEE CAS (2007-2008). He was DL IEEE SSC Society (2009-2010) and currently is DL IEEE CAS Society. He received the 1999 IEEE CAS Society Meritorious Service Award, the 2000 CAS Society Golden Jubilee Medal, and the IEEE Millenium Medal. He was corecipient of the 1996 IEE Fleming Premium, the ESSCIRC 2007 Best Paper Award and the IEEJ Workshop 2007, and 2010 Best Paper Award. 


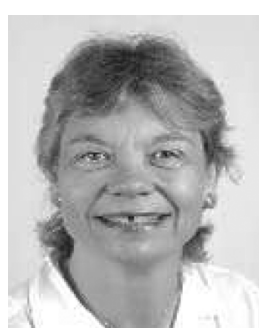

Catherine Dehollain (M'93) received the Master's degree in electrical engineering and the Ph.D. degree from Ecole Polytechnique Fédérale de Lausanne (EPFL), Lausanne, Switzerland, in 1982 and 1995, respectively

From 1982 to 1984, she was a Research Assistant at the Electronics Laboratories (LEG), EPFL. In 1984, she joined the Motorola European Center for Research and Development, Geneva, Switzerland, where she designed integrated circuits applied to telecommunications. In 1990, she joined EPFL as a

Senior Assistant at the haire des Circuits et Systémes, where she was involved in impedance broadband matching. Since 1995, she has been responsible for the RFIC Group, EPFL, for RF activities. She has been the Technical Project Manager of the European projects, CTI projects, and the Swiss National Science Foundation projects dedicated to RF wireless micropower sensor networks and mobile phones. Since 1998, she has been a Lecturer at EPFL in the area of RF circuits, electric filters, and CAD tools. Since 2006, she has been a Maítre d'Enseignement et de Recherche, EPFL. She is an author or coauthor of four scientific books and 110 scientific publications. Her current research interests include low power analog circuits, biomedical remotely powered sensors, and electric filters. 